УДК 81.255

ББК 81.18

DOI: https://doi.org/10.17308/lic.2021.4/3813

\title{
ПЕРЕДАЧА ПЕЙОРАТИВНЫХ ЗНАЧЕНИЙ В ХУДОЖЕСТВЕННОМ ПЕРЕВОДЕ: ИСТОРИЧЕСКИЙ И МЕЖКУЛЬТУРНЫЙ АСПЕКТЫ
}

\author{
К. И. Таунзенд, Н. А. Бонадык \\ Московский государственный лингвистический университет \\ PEJORATIVE WORDS IN LITERARY TRANSLATION:
A HISTORICAL AND A CROSS-CULTURAL PERSPECTIVE
}

K. I. Taunzend, N. A. Bonadyk

Moscow State Linguistic University

\begin{abstract}
Аннотация: в иентре внимания в статье находится пейоративная оценка, выраженная лексическими средствами в художественном тексте и переданная в переводе на другой язык. Передача отрицательных оценочных значений изучается в работе в двух аспектах: в исторической перспективе и применительно к культуре, принципиально отличной от европейской, что в совокупности создает достаточную временну́ю и мировоззренческую дистанцию, позволяющую увидеть общий план. Оба ракурса имеют целью показать возможный спектр переводческих решений в этой области и помогают обозначить приоритеть при переводе высказываний, содержащих пейоративные значения. На примере русского рукописного перевода середины XVIII в. рассматривается, как переводчик передавал пейоративные значения английского романа исходя из определенной литературной традиции своего времени. При явно выраженном стремлении сохранить отрицательную эмоцииональную окраску оригинала здесь проявилась тенденция кусилению пейоративной оценки, уходившая корнями в народную книжную культуру Московской Руси. Примерь из японского перевода пьесы Б. Шоу «Пигмалион» иллюстрируют влияние сочиальных норм поведения и этических представлений принимающей культуры на отражение отрицательной оценки в тексте, хотя и здесь нередко встречаются случаи передачи речевого образа персонажа путем сохранения пейоративных значений в переводе на японский язык. Весь спектр решений переводчиков из разньх эпох и культур от гиперболизации пейоративности оригинала до ее деинтенсификации - показывает, что очевидными приоритетами в работе переводчика при передаче негативных оченочных значений исходного текста должны стать литературная и культурная традиции языка перевода.

Ключевые слова: пейоративная лексика, художественный перевод, история перевода, переводной рукописный роман, «Пигмалион» Б. Шоу, деинтенсификаиия, личные местоимения, некатегоричность.
\end{abstract}

\begin{abstract}
: the article focuses on the pejorative vocabulary of a literary text and the way it is reflected in translation. The transference of pejorative meaning is studied in a historical and a cross-cultural perspective, which creates enough distance in time and outlook to give a panoramic view of the matter. This research aims at the demonstration of the full spectrum of translation techniques in this field and at highlighting the priorities in translation of pejorative utterances. The example of the Russian manuscript translation dating back to the middle of the $18^{\text {th }}$ century shows the influence of the literary tradition of the time on rendering the pejorative meaning of the English novel. While the translator put much effort into keeping the negative emotional colouring of the source text as it was, the tendency towards its intensification revealed itself, being deeply rooted in the ancient Russian folklore. The examples from the Japanese translation of B. Shaw's "Pygmalion" demonstrate the influence of social and ethical norms of the target culture on rendering the pejorative utterances, though the translator often did his best to preserve the initial verbal portrait of the characters. The whole spectrum of translation techniques from different epochs and cultures, ranging from the intensification to neutralization of pejorative meaning of the
\end{abstract}

(C) Таунзенд К. И., Бонадык Н. А., 2021

Контент доступен под лицензией Creative Commons Attribution 4.0 License.

The content is available under Creative Commons Attribution 4.0 License. 
source text, provides enough evidence that the top priorities in translation of pejorative utterances should be the compliance with both literary and cultural traditions of the target audience.

Key words: pejorative vocabulary, literary translation, translation history, manuscript novel translation, B. Shaw's "Pygmalion", deintensification, personal pronouns, non-veridicality.

\section{Введение}

Феномен пейоративного значения, под которым традиционно понимают отрицательный экспрессивно-эмоционально-оценочный компонент коннотации, передающий неодобрение, пренебрежение, иронию или сарказм [1, с. 303], всегда привлекал внимание лингвистики с самых разных сторон: как проявление аксиологических возможностей языка, как средство прагматического воздействия в политическом дискурсе, как способ передачи авторского отношения в художественном тексте, как отличительная черта конкретного регионального или социального диалекта. Однако, на наш взгляд, наибольший интерес вызывает вопрос передачи пейоративных значений в переводе, потому что переводческий процесс по своей природе требует неизбежного сопоставления ресурсов двух языков и культур, а значит, средств и степени выражения пейоративности в них. Поскольку речь здесь идет о проявлении эмоций и неодобрительной оценки в тексте, то становится очевидным, что различия между исходным и принимающим языками могут быть значительны как проистекающие из культурно-обусловленных расхождений между разными языковыми коллективами в сфере выражения неодобрения, пренебрежения и в интенсивности их вербального проявления.

Яркой иллюстрацией подобных различий могут служить случаи, когда лексическая единица в одном языке приобретает с течением времени пейоративное значение, а ее соответствие в другом языке лишено негативной окраски. Так, в русском языке слово планктон выработало за последние годы отрицательную коннотацию, которая проявляет себя, к примеру, в сочетании офисный планктон, в то время как в английском языке его соответствие plankton продолжает функционировать в качестве термина и не обладает оценочной коннотацией [2, с. 235-236]. Это лишь один из множества случаев, которые свидетельствуют об асимметрии пейоративных значений у лексических соответствий в разных языках, что неизбежно требует учета при переводе.

«Сложность позиции переводчика усугубляется тем, что язык перевода может иметь давнюю исторически сложившуюся традицию использования той или иной псевдопейоративной лексемы, насчитывающую десятки, а то и добрую сотню лет. Но и такая традиция не в состоянии противостоять натиску актуальной инфомедиаповестки» [3, с. 161]. Из этого следует, что помимо собственно языковых различий переводчику приходится учитывать сложившиеся этические нормы и культурные традиции выражения пейоративности в обоих лингвосоциумах, с одной стороны, и одномоментный контекст ситуации осуществления перевода с его требованиями и ожиданиями, с другой стороны.

Отсюда происходят многообразные сложности прикладного характера, для преодоления которых требуется теоретическое осмысление приоритетов в действиях переводчика при отражении отрицательных эмоционально-оценочных значений на другом языке. При этом нельзя не отметить крайнюю малочисленность научных работ, которые помогали бы решать прикладные проблемы перевода высказываний с пейоративным значением путем создания теоретических основ для выбора переводческой стратегии отражения пейоративности в разных языках, традициях и культурах. На настоящий момент нам известна одна работа, предлагающая принципы перевода оскорблений, или инвективной лексики, которую можно рассматривать как одно из проявлений неодобрения и пренебрежения в тексте. Автор этой статьи указывает, что ориентирами для переводчика в случае с бранной лексикой должны служить литературная норма, коммуникативный эффект и переводческая целесообразность [4]. Далее он подробно разбирает, как можно руководствоваться каждым из этих параметров при переводе кинофильмов, художественных текстов, публицистики.

В своей статье мы бы хотели внести посильный вклад в теоретическое осмысление приоритетов при передаче пейоративных значений в художественном переводе. Для достижения этой цели мы обратились к наиболее значимым, на наш взгляд, аспектам этой проблемы - зависимости стратегии перевода от исторической традиции выражения пейоративности и от требований культуры языка перевода. Учет этих факторов в практической деятельности переводчика при работе с отрицательными оценочными значениями способствует достижению адекватности перевода, т. е. соответствия переводного текста параметрам ситуации переводческого акта. Иными словами, мы поставили перед собой задачу изучить, как действовали переводчики в разные эпохи и в разных культурах, отражая неодобрение и пренебрежение, выраженное в исходном тексте, в зависимости от господствующей литературной или этической традиции, чтобы на основе анализа их решений попытаться осмыслить стратегию передачи пейоративных значений на другом языке. 


\section{Передача пейоративных значений в истории перевода}

Обращаясь к историческому аспекту отражения пейоративности в переводе, мы выбрали в качестве материала для анализа рукописный перевод романа английской писательницы Сары Филдинг (1710-1768) "The Adventures of David Simple, containing an Account of his Travels through the Cities of London and Westminster, in the Search of a Real Friend", выполненный переводчиком Академии наук Сергеем Саввичем Волчковым (1707 - после 1773/1774) в середине XVIII в. Не останавливаясь здесь подробно на истории создания этого рукописного переводного романа, укажем лишь, что данный текст доступен сегодня в списке конца 60-х - начала 70-х гг. XVIII в. из собрания Н. С. Тихонравова (РГБ. Ф. 299. № 304).

В пятой главе первой книги английского романа автор приводит диалог двух подруг - Miss Nanny

\section{The Adventures of David Simple by Sarah Fielding}

I'm sure if it was my case, I should make no question of preferring a young man I liked to an old decrepid ugly monster, though he was ever so rich. I cannot help laughing at the idea of his figure when ever it comes in my head. In him nature seems perfectly reversed; the calves of his legs are placed before, and his feet are turned inward as it were in spite of nature. One side of his back is high enough to carry the load of riches he possesses; and the other is shrunk in such a manner, that one would imagine his two sides were made only to form a ridiculous contrast. Undoubtedly you would be much envied the possession of so lovely a creature [5, p. 54-55].

I have already told you, if it was my case, I should not hesitate a moment but take the young fellow and let the old wretch purchase what nurse he pleased. He may meet with women enow who have no engagements, and there is no fear that any such would refuse $\operatorname{him}[5$, p. 56].

В приведенных отрывках русский перевод обнаруживает явную тенденцию к гиперболизации пейоративного значения оригинала. Английской отрицательной характеристике an old decrepid ugly monster соответствуют русские словосочетания поганый
Johnson (в русском переводе Мамзель Ионсон) и Miss Betty Trusty (в русском переводе Финеты). Молодые девушки обсуждают жизненно важный для одной из них вопрос о выборе жениха из двух кандидатов, которые через отца Мамзель Ионсон сделали ей предложение. Одним из этих кандидатов является возлюбленный девушки Давид Симпель, главный герой романа, другим - богатый старик Нокес, через родственные узы с которым отец невесты рассчитывает поправить свое материальное положение. Нас же в этом диалоге интересует не сам сюжет (традиционный для женских и любовных романов своего времени), но то пренебрежительное отношение к старому богачу как потенциальному жениху, которое, не скрываясь, выражает подруга и которое с соблюдением литературной традиции эпохи передает русский переводчик XVIII в. Рассмотрим интересующий нас фрагмент.

\section{Истинной друг, или Житие Давида Симпеля (пер. С. С. Волчкова)}

Как тебе добродетельного красавца Симпеля с поганым дедчишкой и мерзким уродом сравнять?! Хотя бы кто, со всех четырех частей света сокровища собравши, перед меня положил, так бы я это плюгавое пужалище не только любить, да и взглянуть на него не хотела! Меня теперь смех берет, как я об этом чучеле подумаю. Совсем угольной мешок! А на человека не похож. Икры у ног его напереди, на берцах горбы, ступени, как у калеки, выломлены, лопатка у правого плеча вывихнута и так далеко от спины отстала, что под нее все алмазы и червонцы его спрячутся. А левая рука, напротив того, так мала и суха, как у мальчика десяти лет. Подлинно, сестрица, что за этим твоим прекрасным Адонисом все знатные дамы и девицы бегать, а тебе завидовать станут! [6, л. 44].

Так я бы часу не мешкав и минуты не думая, за Симпеля пошла, а на гнусного бы урода со всем его богатством плюнула. Пускай он идет к другим, которые из денег всякой день помочи ему подвязывать и пластыри переменять станут. Для чего этот старой дьявол не сватается около таких, которые не сговорены и от всяких обязательств свободны? Поверь мне, ни мало в этом страху нет и не будет, ежели ты этому гнусному пужалищу откажешь [6, л. 46].

дедчиика и мерзкий урод, а выражению the old wretch - фраза гнусныц урод, но другие пейоративные значения переводного текста: плюгавое пужалище, чучело, угольный мешок, на человека не похож, старый дьявол, гнусное пужалище - не имеют соответ- 
ствий в английском оригинале и добавлены переводчиком, очевидно, для усиления чувства пренебрежения в устах персонажа. В результате действующее лицо русского переводного романа выражает свое отрицательное отношение гораздо сильнее и резче, чем его английский прототип, что лишь отчасти может быть связано с большей имплицитностью английского языка по сравнению с русским.

Однако коснувшись вопроса имплицитности/ эксплицитности одного языка относительно другого, мы неизбежно затрагиваем область национальной культуры, что обязывает нас взглянуть на русский текст с точки зрения литературной и исторической традиции, в которой он был создан. И здесь нельзя не вспомнить, что перевод Сергея Саввича Волчкова относится к уникальному типу - типу переводного рукописного романа - «с своим особым переходным характером, близко примыкая, с одной стороны, к рукописному XVII веку», с другой - к печатной литературе восемнадцатого столетия, в то же время отражая традиции народной книги (фольклорных повестей и сказаний) [7, с. i]. Нетрудно заметить, что персонаж русского текста имеет нерусское имя Финета (кстати, данное ей переводчиком), упоминает незнакомого в славянской мифологии прекрасного Адониса, призывает подругу действовать свободно и независимо (даже против воли отца) в выборе мужа, но при этом выражает свое отношение простым и естественным русским языком своего времени. Налицо совмещение традиций - допетровской литературной традиции Московской Руси и зарождающейся по западноевропейским образцам литературы нового времени. Гиперболизация пейоративности в русском переводе XVIII в. была, вероятно, обусловлена старой народной книжной культурой, когда герой недвусмысленно выражал свое неодобрение или пренебрежение, повторяя его в духе русского фольклора на разный лад. Из этого можно сделать вывод, что в исторической перспективе действия переводчика при передаче пейоративных значений оригинала определялись в значительной мере традицией национальной литературы языка перевода, уходящей корнями вглубь веков.

\section{Pygmalion by Bernard Show}

And what are you doing here among all these swells? [8, p. 68].

Оборот all these swells говорит о пренебрежении профессора Хиггинса к собравшимся на рауте аристократам, но в японском переводе используется словосочетание この高貴な方 [ko:ki-na kata] «знатные особы», которое не имеет никакой негативной

\section{Пейоративность в переводе сквозь призму японской культуры}

Перевод всегда включает межкультурный аспект, являясь по сути актом межъязыковой и межкультурной коммуникации, поэтому, осознавая, с одной стороны, некоторую искусственность выделения этого аспекта отдельно, мы попытались обособить инокультурное влияние в процессе перевода, с другой стороны, чтобы тем самым проследить, насколько значимы могут быть культурные представления языка перевода для передачи пейоративных значений оригинала. Указанное обособление межкультурного аспекта потребовало обращения к принципиально отличной от исходного текста культуре. Иными словами, если оригинал принадлежит европейской литературе, то переводной текст должен относиться к неевропейскому (а именно, восточному) мировосприятию.

Исходя из такой постановки задачи, передачу пейоративных значений мы рассмотрим на примере пьесы Б. Шоу «Пигмалион» и ее японского перевода, выполненного К. Одасимой в 2013 г. Выбор пьесы в качестве материала исследования позволяет проанализировать диалоги, возникающие в различных коммуникативных ситуациях, и сопоставить нормы языкового поведения и степень их императивности в английской и японской культурных традициях. Одной из установок японской лингвокультуры является стремление к некатегоричности, что проявляется на различных языковых уровнях: лексическом, морфологическом (модальные связки), синтаксическом (эллипсис). При выполнении перевода на японский язык это нередко приводит к деинтенсифиакации пейоративных оценочных значений в случаях, когда межкультурные различия не позволяют сохранить экспрессивность исходного высказывания в силу его несоответствия социальным нормам, существующим в Японии.

Рассмотрим некоторые примеры деинтенсификации оценочных значений, принимая во внимание их экстралингвистический контекст. Следующая реплика принадлежит грубому и не стесняющемуся в выражениях профессору Хиггинсу, но произносит он ее на светском рауте:

\section{Пигмалион /яп. пер. К. Одасима/}

それで、この高貴な方々の中にまじって何をして いるんだ? [9, p. 153].

(И что ж ты делаешь здесь, среди этих знатных особ $\left.?^{1}\right)$

коннотации, напротив, слово 方 [kata], означающее «человек», используется в случаях, когда говорящий хочет подчеркнуть свое почтительное отношение к

1 Здесь и далее перевод японского варианта выполнен одним из авторов работы. $-H$. Б. 
лицу, о котором идет речь. Таким образом, в японском переводе тенденция «сохранить лицо», находясь в ситуации формального общения, берет верх над стремлением сохранить языковой портрет персонажа. Однако стоит отметить, что здесь, как и на протяжении всего текста, профессор Хиггинс использует в японском переводе неадрессивную форму заключительного глагола, которая обычно употребляется в

Fearful bore for you this sort of thing. Forgive my part in it [8, p. 69].

Переводчик изменил содержание первой, не соответствующей нормам этикета фразы таким образом, что в японском варианте профессор Хиггинс признает неуместность своего поведения, а соответственно, осознает значимость норм этикета для окружающих. Реплика из японского перевода, конечно, не является речевым этикетным клише, но звучит вежливее оригинала. Более того, это один из немногих примеров в переводе пьесы, где профессор Хиггинс использует адрессивную форму глагола, демонстрируя таким

You damned impudent slut, you! [8, p. 104].

Другой пример деинтенсификации - реплика Элизы из первого акта, произнесенная в отношении еще незнакомого ей Хиггинса.

Ought to be ashamed of himself, unmanly coward! [8, p. 15].

Вместо оскорбления unmanly coward в переводе фраза Элизы звучит как укор. Выражение из оригинального текста является одним из средств создания языкового портрета простой, выросшей на улице девушки. В переводе ее принадлежность к низким социальным слоям выдают просторечные грамматические формы (ってんだ [ttenda]) и фонетические искажения (あじ [ајі] вместо はじ [haji]), а возмуще-

Who's hurting you, you silly girl? [8, p. 11].

Oh you a r e a brute. It's a lie: nobody ever saw the sign of liquor on me [8, p. 29].

${ }^{2}$ В японских репликах Элизы Дулиттл встречается множество диалектизмов и просторечий, но так как работа по- ситуациях неформального общения и нередко передается в переводе на русский язык обращением на ты. В случае Хиггинса можно предположить, что выбор такой формы переводчиком обусловлен его желанием передать протест героя против существующих социальных устоев.

Еще один интересный пример - реплика, которую профессор Хиггинс адресует хозяевам вечера:

場違いな人間ですが、来てしまいました。どうぞ お許しください。[9, p. 157].

(Извините, что я пришел, хотя мне здесь не место.)

образом уважение к собеседнику. Очевидно, для переводчика очень важно отразить значимость мероприятия, которая в рамках японской лингвокультуры не допускает полного игнорирования социальных норм.

Обратим внимание, что в других, более непринужденных ситуациях в японском переводе реплик профессора Хиггинса сохраняется даже резкая пейоративная оценка, как в следующем случае, где он обращается к Элизе во время конфликта:

何をこの、生意気な、撥ねっかえりのあばずれめ! [9, p. 233].

(Что, какая нахальная шлюха!)

恥(あじ)を知れってんだ、恥(あじ)を、ったく、 大の男が! [9, p. 39].

(Постыдись, да, постыдись, взрослый же человек!)

ние героини передается при помощи междометия ったく [ttaku], выражающего злость или негодование. При этом грубость по отношению к малознакомому человеку без веской причины, похоже, кажется переводчику избыточной.

Интересными также представляются случаи, где в оригинале объектом оценки является человек, а в переводе - действие, например:

誰が誰をしょっぴくって？バカを言うんじゃな い。 $[9$, p. 31].

(Кто тебя схватит? Не говори глупости.)

えっらそーに、でたらめ言ってんじゃねえや。あ ちしがいつ酒に手え出したっつうんだ。[9, p. 69]. (Как нагло, не говори чепухи! Кто может сказать, что видел, как я выпиваю?²)

священа другому вопросу, мы не ставили перед собой задачу сохранить их в подстрочном переводе. 
Здесь, несмотря на сохранение в переводе в полной мере пейоративной окраски, можно говорить о смягчении оценочного значения, поскольку silly girl и brute выражают перманентную характеристику человека, тогда как фразы バカを言うんじゃない [baka-wo iunjanai] (не говори глупости) и でたらめ言 ってんじゃねえや [detarame iuttenjaneeya] (не говори чепухи) описывают поведение человека в конкретной ситуации, не говоря непосредственно о его личных качествах.

Отдельно можно отметить полисемантичность слова バカ [baka], которое может означать: 1) «дурак, глупый человек», в этом смысле оно использовалось для перевода таких выражений, как foolish ignorant girl, silly girl, idiot, fool; 2) «глупость», в этом значении оно употреблялось как эквивалент nonsense, silly business; 3) «глупый», встречается в тексте в качестве перевода ignorant, stupid, silly. Также バカ входит в состав устойчивого выражения バカにする [baka-ni suru] «глумиться» и образованного от него слова バ カげた [bakageta] «нелепый», которые также используются в переводе. Такое широкое использование バ 力 в качестве эквивалента различных негативно-оце-

Oh, you've no feeling heart in you: you don't care for nothing but yourself [8, p. 30].

Данную реплику произносит Элиза, которая пришла к профессору Хиггинсу просить его о занятиях по фонетике и была возмущена его грубым обращением. Здесь Элиза еще не начала свой путь к превращению в леди, поэтому использует грубые формы. В частности, в ее речи встречаются местоимения あ た и てめえ, несмотря на то, что они традиционно не считаются женскими. Это подчеркивает ее низкий

Now I don't care that for your bullying and your big talk [8, p. 103].

Здесь переводчику важно показать при помощи языковых средств, что Элиза выходит из себя и перестает контролировать свою речь, этот эффект достигается и переходом на неадрессивные формы глаголов (которые она использовала в начале пьесы), и употреблением пейоративного あ $ん$ た, недопустимого для воспитанной

Damn Mrs. Pearce; and damn the coffee; and damn you; and damn my own folly in having lavished MY hard-earned knowledge and the treasure of my regard and intimacy on a heartless guttersnipe [8, p. 79]. ночных лексем может говорить о наличии в английском языке более развитой по сравнению с японским языком системы лексических средств выражения пейоративности.

При этом можно отметить и специфические для японского языка способы передачи оценочных значений. Система личных местоимений японского языка представляет собой многокомпонентный комплекс, в котором представлены синонимы, различающиеся своей стилистической и семантической маркированностью, при этом практически отсутствуют полностью нейтральные варианты. Личные местоимения могут указывать на гендерную принадлежность, возраст говорящего, разницу в социальных статусах участников коммуникации и характер их отношений. В частности, пейоративную оценку выражают употребляемые в тексте перевода местоимения второго лица あ んた [anta], てめえ [temee] и さむ [kisama]. Они используются, чтобы подчеркнуть собственное превосходство и пренебрежение к собеседнику, обычно употребляются мужчинами. В переводе они нужны, чтобы передать общую экспрессивную окраску высказывания. Рассмотрим несколько примеров.

おい、あんたにはおもいやりってもんがねえんか い? てめえのことっきゃ考えてねえ。 [9, p. 71]. (Эй, у тебя что, нет никакого сочувствия? Только о себе и думаешь.)

социальный статус, отсутствие манер. Можно отметить, что あ んた в речи женщин все же употребляются, но в совершенно другом значении, как обращение к близким, возлюбленным или подчиненным (например, хозяйка может обратиться так к прислуге) [10, c. 482]. Элиза же, очевидно, использует именно «мужское» значение. Позднее в ее речи あんた встречается только во время последней ссоры с профессором:

もうかまうこたあねえ、あんたが脅そうが、大口 たたこうが。[9, p. 232].

(Теперь мне плевать на твои угрозы и громкие слова.)

девушки. Заметим, что пейоративные местоимения могут играть роль средства компенсации и брать на себя выражение отрицательно-оценочных значений, которые в оригинале выражены другими способами. Приведем тираду профессора Хиггинса, обращенную после светского раута к «неблагодарной» Элизе:

ピアスがなんだ、コーヒーがなんだ、きさまがな んだってんだ。なんだってオレは、苦労して手に 入れた知識と大切な真心を、こんな薄情なドブネ ズミに与えちまったんだ? [9, p. 180].

(Что мне Пирс, что мне кофе, что мне ты? Да и что мне я сам: отдал такой бесчувственной канавной крысе собранные с огромным трудом знания и свою драгоценную душу?) 
Профессор, вне себя от гнева, обрушивается на Элизу ругательствами. Переводчик сохранил пейоративную окраску второй части фразы, передав heartless guttersnipe как 薄情なドブネズミ[hakujo:-na dobunezumi] (канавная крыса), однако в начале вместо damn используется なんだ [nanda], связка, которая подчеркивает незначительность темы высказывания, но не обладает яркой экспрессивной окраской. Сохранить эмоциональный тон позволяет ис-

Where the devil is that girl? [8, p. 91].

В оригинале отрицательная оценка выражена междометием devil, в переводе же этот эффект достигается путем присоединения к нейтральному глаголу

Well, if you can hear that difference, what the devil are you crying for? [8, p. 50].

В оригинале оценочное значение передается при помощи междометия devil и синтаксической конструкции what are you crying for, в переводе пейоративность сохраняется не только при помощи междометия チク シ $ョ$ - [chikusho:], которое по иллокутивной силе соответствует английскому devil, но также словосочетания ギャーギャ一泣きやがる [gya:-gya: naki-yagaru]. ギャーギャ一 [gya:-gya:] - звукоподражание, которое имитирует плач ребенка или другой раздражающий слух плач, а やがる сообщает возмущение Хиггинса плаксивостью Элизы. Переводчик таким образом стремится передать языковой портрет персонажа, не избегая пейоративных выражений и даже усиливая их для оказания должного воздействия на японского читателя за исключением случаев, когда эта установка вступает в острый конфликт с принятыми требованиями этикета.

Из приведенных выше примеров можно сделать вывод, что в японской лингвокультуре существует ряд ситуаций, в которых пейоративность является крайне нежелательной. Такие ситуации обычно осознанно или непроизвольно учитываются переводчиками. Передача отрицательно-оценочных значений в художественном тексте может также зависеть от того, насколько их сохранение видится переводчику важным для передачи образа персонажа. Система лексических средств выражения пейоративности в японском языке оказалась более ограниченной, чем английская, что может говорить о малой «востребованности» такой лексики. Тем не менее это компенсируется наличием специфических лексических и грамматических средств передачи негативной оценки. пользование местоимения きさま [kisama], одного из самых грубых в ряду пейоративных местоимений 2-го лица.

Среди специфических для японского языка средств выражения пейоративной оценки в тексте в речи профессора Хиггинса встречается также вспомогательный глагол やがる [yagaru], который, присоединяясь к смысловому глаголу, передает презрение или пренебрежение к объекту речи.

どこに行きやがったんだ、あの女？ [9, p. 206].

(И куда она подевалась, эта женщина?)

行く [iku] глагола やがる. Впрочем, возможно его употребление не только как средства компенсации, но и для усиления оценки.

それが分かっててどうしてギャ一ギャ一泣きやが るんだ、チクショー。[9, p. 113].

(Раз понимаешь, зачем же ты ревешь, черт возьми?)

\section{Заключение}

Подводя итог рассмотрению различных подходов к передаче пейоративных значений в художественном переводе, отметим, что, несмотря на кардинальные отличия в выбранных для анализа аспектах, текстах и культурах, переводческие решения обнаруживают значительную долю сходства. И в истории перевода, и в принципиально иной (неевропейской) культуре переводчики всегда стремились по возможности сохранить авторский замысел в случае выражения отрицательной эмоциональной оценки. При этом русский рукописный перевод середины XVIII в. продемонстрировал гиперболизацию пейоративности под влиянием книжной традиции Московской Руси. Coвременные переводы «Пигмалиона» на японский язык позволили выявить, напротив, тенденцию к деинтенсификации пейоративной оценки оригинала там, где она вступала в противоречие с этическими представлениями японцев о поведении в обществе. Из этого становится очевиден вывод о том, что приоритетами для переводчика при передаче пейоративных значений художественного текста должны являться литературная традиция и культурно-закрепленные модели выражения пейоративности в языке перевода, которые, в свою очередь, находятся в тесной связи и взаимозависимости между собой.

\section{ЛИТЕРАТУРА}

1. Ахманова О. С. Словарь лингвистических терминов. М. : Советская энциклопедия, 1966. 608 с.

2. Кислищьна Н. Н. Асимметрия реализации коннотативного потенциала лексем-эквивалентов английского и русского языков // Известия Южного федерального 
университета. Филологические науки. 2016. № 2. С. 233-240.

3. Новицкая $O . B$. Пейоративная лексика и ложная политкорректность // Наука без границ : синергия теорий, методов и практик : материалы Междунар. науч. конф. / отв. ред. О. К. Ирисханова. М., 2020. С. 160-161.

4. Бузаджи Д. М. Норма ненормативного. Ругаемся адекватно // Мосты. Журнал переводчиков. 2006. № 1 (9). М. : Р. Валент, 2006. С. 43-55.

5. Fielding S. The Adventures of David Simple, containing an account of his travels through the cities of London and Westminster, in the Search of a Real Friend. By a Lady. In two volumes. Vol. 1. London : Printed for T. Davis, 1772. $278 \mathrm{p}$.

6. Истинный друг, или житие Давида Симпеля [рукопись] / пер. с англ. С. С. Волчкова. [Б. м.], XVIII в. 180 л.

7. Пыпин А. Н. Для любителей книжной старины. Библиографический список рукописных романов, повестей, сказок, поэм и пр., в особенности из первой половины XVIII века. М. : Типолитография И. Н. Кушнерева, $1888.74 \mathrm{c}$.

8. Show B. Pygmalion. London : Longmans, Green and Co Ltd, 1969. 150 p.

9. Sho B. Pigumarion. Tokyo : Kobunsha, 2013. 297 p. (In Japanese.)

10. Алпатов В. М., Аркадьев П. М., Подлесская В. И. Теоретическая грамматика японского языка : в 2 кн. Кн. 1. М. : Наталис, 2008. 560 с.

\section{REFERENCES}

1. Akhmanova O. S. Slovar' lingvisticheskikh terminov [Dictionary of linguistic terminology]. M.: Sovetskaya ehntsiklopediya, 1966. $608 \mathrm{~s}$.

2. Kislitsyna N. N. Asimmetriya realizatsii konnotativnogo potentsiala leksem-ehkvivalentov anglijskogo i

Московский государственный лингвистический университет

Таунзенд К. И., кандидат филологических наук, доиент, доиент кафедры переводоведения и практики перевода английского языка

E-mail: townsendX@yandex.ru

Бонадык Н. А., преподаватель кафедры восточных языков

E-mail: nat5000@yandex.ru

Поступила в редакциюю 2 сентября 2021 г.

Принята к публикачии 15 октября 2021 2.

\section{Для цитирования:}

Таунзенд К. И., Бонадык Н. А. Передача пейоративных значений в художественном переводе: исторический и межкультурный аспекты // Вестник Воронежского государственного университета. Серия: Лингвистика и межкультурная коммуникация. 2021. № 4. С. 73-80. DOI: https://doi.org/10.17308/lic.2021.4/3813 russkogo yazykov [Asymmetry of connotative potential realization of lexem-equivalents of the English and Russian languages]. In: Izvestiya YUzhnogo federal'nogo universiteta. Filologicheskie nauki. 2016. No. 2. Pp. 233240.

3. Novitskaya O. V. Pejorativnaya leksika i lozhnaya politkorrektnost' [Pejorative vocabulary and wrong political correctness]. In: Nauka bez granits: sinergiya teorij, metodov i praktik: materialy Mezhdunarodnoj nauchnoj konferentsii. otv. red. O. K. Iriskhanova. M., 2020. Pp. 160-161.

4. Buzadzhi D. M. Norma nenormativnogo. Rugaemsya adekvatno [The norm of the abnormal. Let's swear properly]. In: Mosty. ZHurnal perevodchikov. 2006. No. 1 (9). M.: R. Valent, 2006. Pp. 43-55.

5. Fielding S. The Adventures of David Simple, containing an account of his travels through the cities of London and Westminster, in the Search of a Real Friend. By a Lady. In two volumes. Vol. 1. London: Printed for T. Davis, 1772. $278 \mathrm{p}$.

6. Istinnyj drug ili zhitie Davida Simpelya [rukopis'] [A real friend or the life of David Simple]. per. s angl. S. S. Volchkova. [B. m.], XVIII v. 1801.

7. Pypin A. N. Dlya lyubitelej knizhnoj stariny. Bibliograficheskij spisok rukopisnykh romanov, povestej, skazok, poehm i pr., v osobennosti iz pervoj poloviny XVIII veka. [Bibliographical list of $18^{\text {th }}$ century manuscript fiction]. M.: Tipolitografiya I. N. Kushnereva, 1888. 74 p.

8. Show B. Pygmalion. London: Longmans, Green and Co Ltd, 1969. 150 p.

9. Sho: B. Pigumarion. Tokyo: Kobunsha, 2013. 297 p. (In Japanese.)

10. Alpatov V. M., Arkad'ev P. M., Podlesskaya V. I. Teoreticheskaya grammatika yaponskogo yazyka. V $2 \mathrm{kn}$. Kn. 1. [Theoretical grammar of the Japanese language]. M.: Natalis, 2008. 560 p.

Moscow State Linguistic University

Taunzend K. I., Candidate of Philology, Associate Professor of the Translation Studies and Translation and Interpreting (the English Language) Department

E-mail: townsendX@yandex.ru

Bonadyk N. A., Lecturer of the Oriental Languages Department

E-mail: nat5000@yandex.ru

Received: 2 September 2021

Accepted: 15 October 2021

\section{For citation:}

Taunzend K. I., Bonadyk N. A. Pejorative words in literary translation: a historical and a cross-cultural perspective. Proceedings of Voronezh State University. Series: Linguistics and Intercultural Communication. 2021. No. 4. Pp. 73-80. DOI: https://doi.org/10.17308/lic.2021.4/3813 